\title{
Effect of Minimally Invasive Spine Stabilization in Metastatic Spinal Tumors
}

\author{
Kazuo Nakanishi *(D), Kazuya Uchino, Seiya Watanabe, Kosuke Misaki and Hideaki Iba
}

check for updates

Citation: Nakanishi, K.; Uchino, K.; Watanabe, S.; Misaki, K.; Iba, H. Effect of Minimally Invasive Spine Stabilization in Metastatic Spinal Tumors. Medicina 2022, 58, 358. https://doi.org/10.3390/ medicina58030358

Academic Editor: Yoshihisa Kotani

Received: 19 January 2022

Accepted: 27 February 2022

Published: 1 March 2022

Publisher's Note: MDPI stays neutral with regard to jurisdictional claims in published maps and institutional affiliations.

Copyright: (C) 2022 by the authors. Licensee MDPI, Basel, Switzerland. This article is an open access article distributed under the terms and conditions of the Creative Commons Attribution (CC BY) license (https:// creativecommons.org/licenses/by/ $4.0 /)$.

\author{
Department of Orthopedics, Traumatology and Spine Surgery, Kawasaki Medical School, \\ Okayama 701-0192, Japan; kazuya_u@med.kawasaki-m.ac.jp (K.U.); seiya-w@med.kawasaki-m.ac.jp (S.W.); \\ k-misaki@med.kawasaki-m.ac.jp (K.M.); i-hideaki@med.kawasaki-m.ac.jp (H.I.) \\ * Correspondence: k.nakanishi@med.kawasaki-m.ac.jp; Tel.: +81-86-462-1111
}

\begin{abstract}
Background and Objectives: There have been numerous advances in spine surgery for metastatic spinal tumors, and minimally invasive spine stabilization (MISt) is becoming increasingly popular in Japan. MISt is a minimally invasive fixation procedure that temporarily stabilizes the spine, thereby reducing pain, preventing pathological fractures, and improving activities of daily living at an early stage. MISt may be useful given the recent shift toward outpatient cancer treatment. Materials and Methods: This study enrolled 51 patients with metastatic spinal tumors who underwent surgery using MISt between December 2013 and October 2020. The Spinal Instability Neoplastic Score, an assessment of spinal instability, was used to determine the indication for surgery, and the Epidural Spinal Cord Compression scale was used for additional decompression. Results: The patients comprised 34 men and 17 women, and the mean age at surgery was 68.9 years. The mean postoperative follow-up period was 20.8 months, and 35 of 51 patients (67\%) had died by the last survey. The mean operative time was $159.8 \mathrm{~min}$, mean blood loss was $115.7 \mathrm{~mL}$, and mean time to ambulation was 3.2 days. No perioperative complications were observed, although two patients required refixation surgery. Preoperatively, 37 patients $(72.5 \%)$ were classified as Frankel grade E. There were no cases of postoperative exacerbation, and six patients showed improvement of one or more Frankel grades after surgery. The median duration of patient survival was about 22.0 months. Patients with breast, prostate, renal, and thyroid cancers had a good prognosis, whereas those with gastrointestinal and head and neck cancers had a poor prognosis. Conclusions: MISt can benefit patients who are ineligible for conventional, highly invasive surgery and is also suitable because cancer treatment is increasingly performed on an outpatient basis. Furthermore, choosing the right surgery for the right patient at the right time can significantly affect life expectancy.
\end{abstract}

Keywords: metastatic spinal tumor; minimally invasive spine stabilization; percutaneous pedicle screw; skeletal-related event

\section{Introduction}

Cancer treatment has changed drastically over the past decade. Advances in therapies include molecular-targeted drugs, immune checkpoint inhibitors, bone-modifying agents, chemotherapy, and radiotherapy. Multidisciplinary and systemic treatments have also started being used. These developments have significantly improved life expectancy, and we are now living in an era of coexistence with cancer, with shorter hospitalization periods and a shift of treatment to outpatient settings.

The effects of metastatic spinal tumors differ from those of other bone metastases. The occurrence of skeletal-related events (SREs) [1,2], such as fractures and paralysis, can significantly impair activities of daily living (ADLs) and reduce quality of life (QOL). If ADLs are impaired, patients may not be eligible for chemotherapy or radiotherapy, which may affect their life expectancy $[3,4]$ and hinder the transition of treatment to an outpatient setting. 
Conventional spinal surgery for metastatic spinal tumors is highly invasive and requires a long hospital stay to stabilize the spine and relieve nerve compression caused by the tumor. In recent years, however, there have been significant advances in spinal surgeries. Minimally invasive surgeries and locally curative surgeries such as total en bloc spondylectomy (TES) [5] have become more common. Minimally invasive spine stabilization (MISt) using percutaneous pedicle screw (PPS) fixation of the spine, which has been performed relatively frequently in Japan since 2005, is indicated for cancer-bearing patients with impaired systemic reserves. In this context, MISt is a minimally invasive fixation technique that uses PPSs to temporarily stabilize the spine, thus reducing pain and facilitating early improvement in ADLs. It can also prevent pathological fractures and is useful given the current transition to outpatient treatment. This article describes the efficacy of the MISt procedure in patients with metastatic spinal tumors.

\section{Materials and Methods}

This study was a retrospective study, conducted according to the guidelines of the Declaration of Helsinki and approved by the Institutional Review Board of our hospital (ID: 5054-01, 20 October 2020). A total of 51 consecutive patients with metastatic spinal tumors underwent surgery at our hospital from December 2013 to October 2020.

\subsection{Indication for Surgery}

We provided multidisciplinary therapeutic intervention for all metastatic spine tumors [6]. Once metastasis was detected in the spine, the spinal surgeon intervened to determine the treatment plan. Eligibility for surgery was determined by comprehensive patient evaluations performed by attending doctors and specialists and was also based on prognosis. In general, for patients without paralysis whose main symptom was pain, radiotherapy was the first-line treatment. In order to clarify the indication for surgery, spinal instability was evaluated using a spinal instability neoplastic score (SINS) [7] at our hospital. Surgery was recommended for patients with SINS score $\geq 13$. In SINS, the indication for surgery in cases of imminent instability of 7 to 12 points became a problem. For impending spinal instability defined by a SINS score between 7 and 12, surgery was selected if imaging studies showed vertebral collapse or osteolysis of the posterior wall of the vertebral body or the pedicle of the vertebral arch or if ambulation was impossible because of severe pain. In principle, surgery was indicated for patients with a well-controlled primary tumor or for whom there were additional treatment options.

\subsection{Surgical Technique}

Preoperative evaluation and careful preoperative planning were considered important. Cancer is a systemic disease, and the first step was to evaluate the general condition of the patient. Surgery was contraindicated for bone marrow carcinosis, a condition that causes abnormalities of the blood and hematopoietic organs due to metastasis of tumor cells to the bone marrow. MRI was used to evaluate tumor spread to the vertebral bodies, and bone scintigraphy was used to evaluate systemic metastasis. Since patients with multiple spinal metastases are inevitably targeted, long fusion was often used. The range of spinal fusion and the size of the screw were decided in advance, so as to reduce the durations of surgery and radiation exposure.

Surgery was conducted according to the standard MISt procedure with commonly used PPSs [8]. The fusion range was basically three vertebrae above and two below. In principle, screws were not inserted into metastatically involved vertebral bodies. Additional decompression was performed in patients with neurological symptoms and those with grade $\geq 2$ lesions based on the Epidural Spinal Cord Compression scale [9]. During decompression, the implant was placed first, and then all wounds were closed. The decompression procedure was then performed with a separate skin incision in the midline. Bone grafting was generally not performed. 
The outcome and the following items were evaluated: (1) operative time; (2) blood loss; (3) time to ambulation; (4) Tokuhashi score [10] and New Katagiri score [11] to evaluate prognosis; (5) SINS to evaluate the stability of the vertebral body [7]; (6) Frankel grade to assess the degree of spinal cord injury; and (7) Eastern Cooperative Oncology Group Performance status (PS) [12] to evaluate QOL. The association of each parameter with the outcome was assessed using the Mann-Whitney $U$ test, and survival time was calculated from the date of enrollment to the date of death using the Kaplan-Meier method. Statistical analyses were conducted using SPSS software, version 23.0 (IBM Japan Business Services Co., Ltd., Tokyo, Japan), with a significance level of $5 \%$.

\section{Results}

Table 1 shows the patient characteristics. The mean age of all subjects $(n=51$; male, $\mathrm{n}=34$; female, $\mathrm{n}=17$ ) was $68.9 \pm 9.9$ years (range: $44-81$ years). The primary tumors were breast cancer $(n=11)$, lung cancer $(n=10)$, prostate cancer $(n=7)$, gastrointestinal cancer $(n=5)$, renal pelvis/ureter cancer $(n=4)$, kidney cancer $(n=3)$, thyroid cancer $(n=2)$, uterine cancer $(n=2)$, multiple myeloma $(n=2)$, primary unknown cancer $(n=2)$, pancreatic cancer $(n=1)$, head and neck cancer $(n=1)$, and others $(n=1)$. The mean postoperative follow-up period was $20.8 \pm 21.8$ months (range: $1-87$ months), and 35 of $51(67 \%)$ patients died before the final follow-up. Follow-up was successfully completed in 44 of $51(86.3 \%)$ patients.

Table 1. Detailed clinical characteristics and results of patients with metastatic spine tumors who underwent MISt surgery.

\begin{tabular}{|c|c|}
\hline & MISt \\
\hline Patients, $\mathrm{n}$ & 51 \\
\hline Gender & Male 34; female 17 \\
\hline Age at diagnosis of metastatic spinal tumors, years & $68.9 \pm 9.9$ \\
\hline Postoperative follow-up period, months & $20.8 \pm 21.8$ \\
\hline \multicolumn{2}{|l|}{ Metastatic tumor diagnosis, $\mathrm{n}(\%)$} \\
\hline Breast cancer & $11(21.6)$ \\
\hline Lung cancer & $10(11.4)$ \\
\hline Prostate cancer & $7(4.7)$ \\
\hline Gastrointestinal cancer & $5(9.8)$ \\
\hline Renal pelvis/ureter cancer & $4(7.8)$ \\
\hline Kidney cancer & $3(5.9)$ \\
\hline Thyroid cancer & $2(3.9)$ \\
\hline Uterine cancer & $2(3.9)$ \\
\hline Multiple myeloma & $2(3.9)$ \\
\hline Primary unknown cancer & $2(3.9)$ \\
\hline Pancreatic cancer & $1(2.0)$ \\
\hline Head and neck cancer & $1(2.0)$ \\
\hline Others & $1(2.0)$ \\
\hline SINS & $9.4 \pm 2.8$ \\
\hline Tokuhashi score & $9.3 \pm 2.6$ \\
\hline New Katagiri score & $4.6 \pm 2.0$ \\
\hline PS (preop) & $2.5 \pm 1.3$ \\
\hline Number of deaths, n (\%) & $35(68.6 \%)$ \\
\hline \multicolumn{2}{|l|}{ Adjuvant therapy } \\
\hline Radiotherapy (RT) & $46(90.2 \%)$ \\
\hline Bone-modifying agents & $41(80.4 \%)$ \\
\hline
\end{tabular}

SINS, spinal instability neoplastic score ${ }^{7)}$; PS, performance status. PS was evaluated using the Eastern Cooperative Oncology Group Performance status (ECOG PS) scale ${ }^{12}$.

With regard to prognostic prediction scores, the mean Tokuhashi score was $9.3 \pm 2.6$ (range: 5-14), and the mean New Katagiri score was $4.6 \pm 2.0$ (range: $1-9$ ).

For each patient, the treatment strategy was determined based on the total score of the six SINS items, including lesion location, pain, and vertebral collapse [7]. Given a 
maximum score of 18 points, a score of $\leq 6$ points was classified as stable condition, 7 to 12 points was impending spinal instability, and $\geq 13$ points was instability. The mean SINS score was $9.4 \pm 2.8$ (range: $3-16$ ).

Table 2 displays the surgical details. The mean number of fixed intervertebral segments was 6 (range: $2-16$ ). Additional decompression was performed in 14 patients. The mean operative time was $159.8 \pm 65.4 \mathrm{~min}$ (range: $52-410 \mathrm{~min}$ ), mean blood loss volume was $115.7 \pm 126.7 \mathrm{~mL}$ (range: $10-630 \mathrm{~mL}$ ), and mean time to ambulation (excluding three patients) was $3.2 \pm 2.2$ days (range: 1-14 days). The relationship between additional decompression and the SINS score is shown in Table 3. Two-thirds of unstable patients with a score of $\geq 13$ points underwent additional laminectomy. Most patients with a score $<12$ points underwent temporary fixation only.

Table 2. Details of the surgery.

\begin{tabular}{cc}
\hline Operative time (minutes) & $159.8 \pm 65.4$ \\
Blood loss (mL) & $115.7 \pm 126.6$ \\
Fixed segments (vertebrae) & 6.2 \\
Additional decompression & 14 \\
Ambulation (days) & $3.2 \pm 2.2$ \\
PS (preop) & $2.5 \pm 1.3$ \\
PS (postop) & $1.7 \pm 1.3$ \\
Discharge (cases) & 31 \\
Transferred to another hospital (cases) & 17
\end{tabular}

PS, performance status. PS was evaluated using the Eastern Cooperative Oncology Group Performance status (ECOG PS) scale ${ }^{12)}$.

Table 3. Details of preoperative SINS evaluation and additional laminectomy.

\begin{tabular}{cccc}
\hline SINS & Assessment of Spinal Instability & Cases & Additional Decompression, n (\%) \\
\hline $0-6$ & Stability & 7 & $2(28.6)$ \\
$7-12$ & Imminent instability & 38 & $8(21.1)$ \\
$\geq 13$ & Instability & 6 & $4(66.7)$ \\
\hline
\end{tabular}

SINS, spinal instability neoplastic score ${ }^{7)}$.

No systemic complications were observed in the perioperative period, although three patients required further surgery. Two patients had loosened screws, and one patient had metastases detected in other parts of the body, each of whom underwent additional surgery. As concomitant treatments, $46(90 \%)$ patients received radiotherapy (RT) and $41(80 \%)$ received a bone-modifying agent.

Table 4 shows the preoperative and postoperative Frankel grades. 37 (72.5\%) patients had a preoperative Frankel grade of E (no paralysis). Three patients were classified as Frankel grade A, four as grade C, and seven as grade D. There were no cases of postoperative exacerbation, and six patients improved postoperatively by at least one grade.

Table 4. Improvement of paralysis by Frankel's classification before and after surgery.

\begin{tabular}{cccccc}
\hline Frankel & A & B & C & D & E \\
\hline A & 2 & & & 1 & \\
B & & 0 & 3 & 1 & 2 \\
C & & & & 5 & 37 \\
D & & & & & \\
E & & & & & \\
\hline
\end{tabular}

The vertical axis is the preoperative Frankel's classification, and the horizontal axis is the postoperative Frankel's classification.

The mean PS was $2.5 \pm 1.3$ before surgery, which significantly improved to $1.7 \pm 1.3$ after surgery $(p<0.01) .31$ patients were discharged home (mean time from surgery to 
discharge: $31.9 \pm 18.0$ days), and 17 patients were transferred to another hospital (mean time from surgery to transfer: $39.4 \pm 7.0$ days).

Among the 51 patients receiving MISt, the median duration of survival was about $22.0 \pm 8.6$ months (95\% confidence interval [CI] 5.1-38.8; Figure 1).

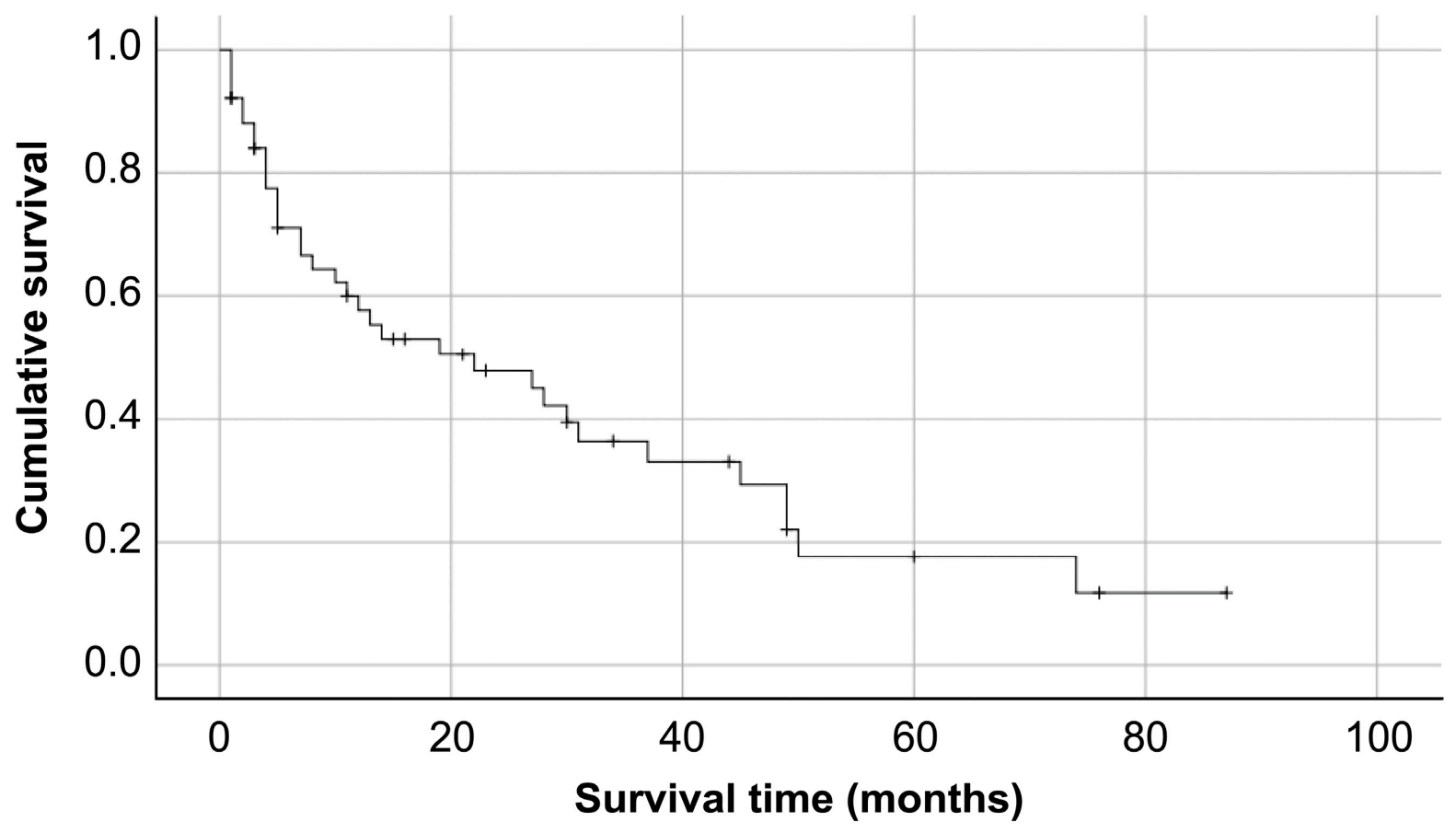

Figure 1. Kaplan-Meier curve for survival in MISt, $22.0 \pm 8.6$ months (95\% confidence interval [CI] 5.1-38.8).

We analyzed the characteristics of the eight patients who experienced early death, defined as occurring within 3 months postoperatively (Table 5). Four of these patients were first seen after the onset of SRE. The type of carcinoma varied, and the mean SINS score was $10.1 \pm 3.8$ points (range: $3-16$ ), indicating imminent instability. The mean preoperative PS was $2.4 \pm 1.2$ (range: $0-4$ ), and the mean postoperative PS was $2.0 \pm 1.6$ (range: $0-4$; $p>0.05)$. Three patients were discharged home, two were transferred to another institution, and the others died during hospitalization. Surgery was not the direct cause of death in any of the cases.

Table 6 shows the mortality by cancer type. The prognosis was favorable in patients with breast, prostate, kidney, or thyroid cancer but was poor in those with cancers of the digestive system or head and neck. Therefore, the underlying disease should be considered when determining the eligibility of patients for surgery.

\section{Case Presentation}

A 63-year-old woman with metastatic spinal tumors secondary to breast cancer (Figure 2) was referred for weakness of the left lower extremity (Frankel grade D) and gait disturbance. Multiple metastases in the ribs and pelvis were also observed. The Tokuhashi score was 10 points, the New Katagiri score was 6 points, and the PS was 4 . Decompression surgery was performed at T7-8, and screws were inserted and fixed in the unaffected vertebrae (C3-L2). The operation time was $410 \mathrm{~min}$, and blood loss was $210 \mathrm{~mL}$ The patient began walking on the second postoperative day, and radiotherapy was started on postoperative day 15. The patient's paralysis of the lower limbs improved, PS improved to 2 , and she was discharged home on postoperative day 60 . The patient died 3 years 8 months after the surgery, but no loosening of the screw was observed until the patient's death. 
Table 5. Cases of early death.

\begin{tabular}{|c|c|c|c|c|c|c|c|c|}
\hline Cases & 1 & 2 & 3 & 4 & 5 & 6 & 7 & 8 \\
\hline Age & 0 & 72 & 46 & 81 & 62 & 63 & 79 & 67 \\
\hline Gender & M & M & $\mathrm{F}$ & M & M & M & M & M \\
\hline Primary Tumors & $\begin{array}{l}\text { Esophageal } \\
\text { cancer }\end{array}$ & $\begin{array}{l}\text { Renal pelvis } \\
\text { cancer }\end{array}$ & Uterine sarcoma & $\begin{array}{l}\text { Multiple } \\
\text { myeloma }\end{array}$ & $\begin{array}{l}\text { Primary unknown } \\
\text { cancer }\end{array}$ & Colon cancer & Lung cancer & Gastric cancer \\
\hline SINS & 14 & 9 & 3 & 7 & 12 & 16 & 10 & 10 \\
\hline Frankel grade & $\mathrm{D}$ & $\mathrm{E}$ & $\mathrm{E}$ & $\mathrm{E}$ & $\mathrm{D}$ & $\mathrm{E}$ & $\mathrm{E}$ & $\mathrm{E}$ \\
\hline Tokuhashi & 7 & 13 & 13 & 8 & 6 & 11 & 5 & 7 \\
\hline New Katagiri & 9 & 3 & 2 & 2 & 6 & 7 & 8 & 5 \\
\hline PS (post-op) & 4 & 0 & 0 & 4 & 3 & 3 & 1 & 1 \\
\hline Postoperative period & 1 & 1 & 1 & 1 & 2 & 2 & 3 & 3 \\
\hline $\begin{array}{l}\text { Consult to } \\
\text { orthopedic surgery }\end{array}$ & $\begin{array}{l}\text { Detected by } \\
\text { imaging tests }\end{array}$ & $\begin{array}{l}\text { Detected by } \\
\text { imaging tests }\end{array}$ & $\begin{array}{l}\text { Detected by } \\
\text { imaging tests }\end{array}$ & $\begin{array}{l}\text { After the onset of } \\
\text { SRE }\end{array}$ & $\begin{array}{l}\text { After the onset of } \\
\text { SRE }\end{array}$ & $\begin{array}{c}\text { After the onset of } \\
\text { SRE }\end{array}$ & $\begin{array}{l}\text { After the onset of } \\
\text { SRE }\end{array}$ & $\begin{array}{l}\text { Detected by } \\
\text { imaging tests }\end{array}$ \\
\hline Outcome & * & * & $\begin{array}{l}25 \text { days } \\
\text { transferred to } \\
\text { another hospital }\end{array}$ & * & $\begin{array}{c}35 \text { days } \\
\text { transferred to } \\
\text { another hospital }\end{array}$ & $\begin{array}{c}39 \text { days } \\
\text { discharged home }\end{array}$ & $\begin{array}{c}31 \text { days } \\
\text { discharged home }\end{array}$ & $\begin{array}{c}20 \text { days } \\
\text { discharged home }\end{array}$ \\
\hline Cause of death & Brain metastasis & Sepsis & $\begin{array}{l}\text { Deterioration of } \\
\text { general condition }\end{array}$ & $\begin{array}{l}\text { Aspiration } \\
\text { pneumonia }\end{array}$ & $\begin{array}{l}\text { Deterioration of } \\
\text { general condition }\end{array}$ & Liver metastasis & AMI & $\begin{array}{l}\text { Deterioration of } \\
\text { general condition }\end{array}$ \\
\hline
\end{tabular}


Table 6. Mortality by cancer type.

\begin{tabular}{ccccc}
\hline Primary Tumors & Number of Cases & Number of Deaths & Mortality Rate (\%) & Postoperative Period (Months) \\
\hline Breast cancer & 11 & 5 & 45.4 & 39.6 \\
Lung cancer & 10 & 9 & 90 & 16.5 \\
Prostate cancer & 7 & 2 & 28.6 & 27.7 \\
Gastrointestinal cancer & 5 & 5 & 100 & 2.4 \\
Ureter cancer & 4 & 3 & 75 & 9.3 \\
Kidney cancer & 3 & 1 & 33.3 & 38.7 \\
Thyroid cancer & 2 & 2 & 100 & 7.5 \\
Uterine cancer & 2 & 2 & 100 & 6.5 \\
Multiple myeloma & 2 & 2 & 100 & 1.5 \\
Primary unknown & 2 & 1 & 50 & 5 \\
cancer & 1 & 1 & 100 & 1 \\
Pancreatic cancer & 1 & 1 & 100 & 4 \\
Head and neck cancer & 1 & 1 & 100 & \\
Others & & & & \\
\hline
\end{tabular}

(A)

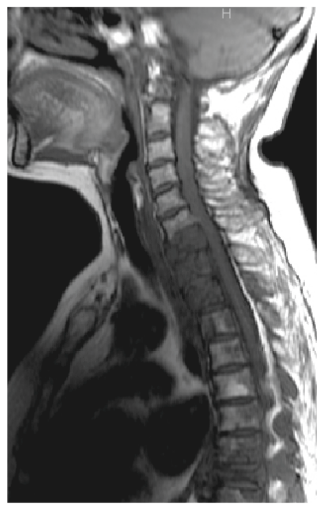

(D)
(B)

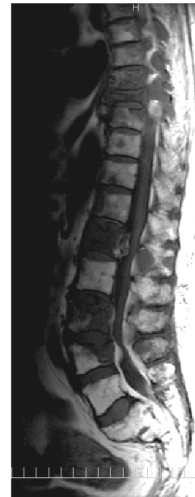

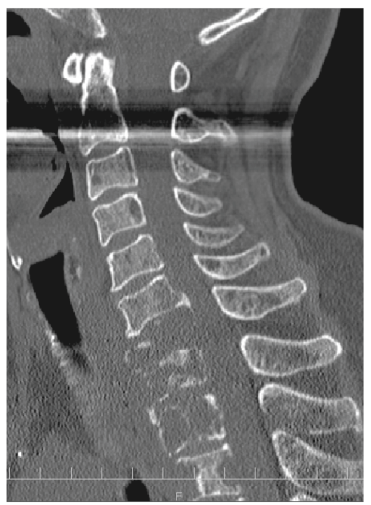

(C)

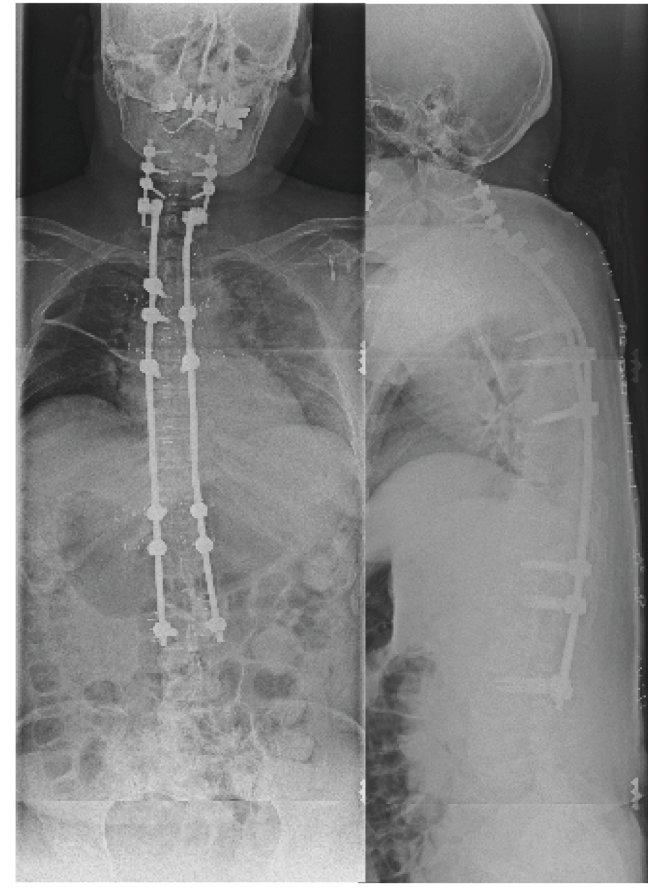

Figure 2. Case. A 63-year-old woman with metastatic spinal tumor of breast cancer. (A) Radiographs showing the first augmentation surgery. (B) Preoperative computed tomography (CT) image. (C) Radiograph showing the whole spine after surgery. (D) CT image at 43 months after surgery (C3, T12, L2 level).

\section{Discussion}

Due to advances in cancer therapies, the prognosis of patients with cancer has improved. Thus, there is a need to extend the healthy life expectancy of patients with metastatic spinal tumors by maintaining ADLs and enhancing QOL. Previously, conventional surgery for metastatic spinal tumors has consisted of spinal decompression and fixation, which required a large incision. As a result, this surgery necessitated a long hospitalization and postoperative bed rest and delayed the transition to other treatments such as radiation therapy and chemotherapy. As conventional surgery is highly invasive, patients' eligibility for surgery depends on their systemic reserves and life expectancy. 
Ineligible patients often develop SREs [1,2], such as pathological fracture and paralysis. Significant impairment of ADLs and QOL due to SREs leads to ineligibility for radiotherapy and chemotherapy and consequently affects life expectancy.

For patients with spinal metastases who have good PS, who have no metastases in the principal organs, and in whom the tumors are localized to the vertebral bodies, curative surgery such as TES [5] is preferable. However, only a small number of patients are eligible for this procedure. In many cases, the only option is to perform minimally invasive palliative surgery [10]. Although no eligibility criteria for life expectancy have been established with regard to surgery for metastatic spinal tumors, some studies have suggested that conventional, highly invasive surgery requires a tolerable general condition and a life expectancy of 6 months or longer $[5,10]$.

MISt is performed for treating trauma, infection, metastatic spinal tumors, and scoliosis. In particular, it is the best treatment option for patients with metastatic spinal tumor who have a limited life expectancy [8,13-15]. As MISt allows for early postoperative ambulation and discharge, its indication has been extended to patients with a life expectancy of less than 6 months. Furthermore, MISt allows for early postoperative adjuvant therapies, such as radiotherapy and chemotherapy.

Based on our experience with MISt to date, the technique demonstrates three advantages for the treatment of metastatic spinal tumor:

1. MISt is less invasive than conventional surgery. This leads to reduced bleeding and not only allows patients to recover from surgery earlier but also makes it possible to perform surgery in patients who are ineligible for conventional surgery because of poor systemic reserves. Miscusi et al. [16] found that the mean operative times was $3.2 \mathrm{~h}$ in patients treated with the conventional method versus $2.2 \mathrm{~h}$ in those undergoing minimally invasive spine surgery (MISS; $p<0.01$ ); the mean intraoperative blood losses were $900 \mathrm{~mL}$ and $240 \mathrm{~mL}$, respectively, and the mean durations of postoperative bed rest were 4 days and 2 days ( $p<0.01$ ), respectively. No patients in the MISS group required blood transfusions. Watanabe et al. [17] studied the results of 112 patients who underwent conventional surgery and who differed in terms of their preoperative ambulatory status. The ambulatory and non-ambulatory groups had mean intraoperative blood losses of $960 \mathrm{~mL}$ (20-3420 mL) and $1230 \mathrm{~mL}$ (230-3090 mL), respectively, and mean operative times of $199 \mathrm{~min}(60-975 \mathrm{~min}$ ) and $259 \mathrm{~min}(100-685 \mathrm{~min})$, respectively. In our hospital, MISt surgery was associated with a mean operative time of $159.8 \pm 65.4 \mathrm{~min}(52-410 \mathrm{~min})$, a mean blood loss of $115.7 \pm 126.7 \mathrm{~g}(10-630 \mathrm{~g})$, and a mean duration of postoperative bed rest of $3.2 \pm 2.2$ days (1-14 days). It had also been reported that MISt has lower transfusion volume and fewer complications compared to the conventional spinal surgery $[18,19]$. This indicates that MISt can be used in more cases, even in elderly patients and those with a prognosis of $\leq 6$ months. In other words, MISt will open up opportunities for patients who are ineligible for conventional surgical methods because of their high invasiveness.

2. MISt results in early postoperative ambulation and early discharge. This is a very helpful benefit for patients with metastatic spinal tumors because their life expectancy is limited. Miscusi [16] reported that the average length of hospital stay was 7.2 days in the MISS group $(p<0.01)$ and 9.25 days in the conventional method group. Cui also reported that the average length of hospital stay for conventional and MIS surgery was 8.8 and 11.3 days, respectively [19]. At our hospital, 31 of 51 patients were discharged home after surgery (mean $31.9 \pm 18.0$ days after surgery), and 17 were transferred to another institution (mean $39.4 \pm 7.0$ days after surgery). The reason why our hospital stay was longer than other reports was that the primary physician for the hospital stay was basically the oncologist, not the orthopedic surgeon, due to multidisciplinary treatment [6]. The advantage was that the oncology department could start treatment as soon as possible, while the primary physician had a long hospital stay to introduce other adjuvant therapies after the surgery. Furthermore, because increasing numbers of adjuvant therapies are now being administered or performed on an outpatient 
basis, we believe that MISt provides a great advantage by allowing early discharge from the hospital.

3. MISt allows fixation with less contamination and does not interfere with other adjuvant therapies. If only fixation is performed, contamination is almost irrelevant because the affected area is not expanded. In addition, there is less damage to soft tissues and so forth, and early transition to anticancer drugs and radiation therapy is possible. If decompression is not added, the patient can be immobilized so as to avoid the irradiated area, thus preventing complications such as skin problems, even if radiotherapy is started early after surgery. Zairi et al. [20] wrote that the most important benefit of using minimally invasive approaches is the more rapid initiation of postoperative adjuvant therapies. Conventional methods require wide exposure, resulting in a large dead space and tissue necrosis. For these reasons, Zairi et al. [20] stated that adjuvant therapy should not be started until 4-5 weeks after surgery to prevent wound dehiscence and infection. At our hospital, we consider that MISt can avoid complications such as skin problems even if radiotherapy is started early after surgery, because it can be fixed in a way that avoids areas that can be irradiated. Moreover, if detected early through multidisciplinary treatment, interventions can be made before nerve compression or pathological fractures occur, thus eliminating the need for decompression surgery.

On the other hand, there are some disadvantages of MISt for metastatic spinal tumor:

1. MISt carries risks and is dependent on surgeon skill. It is challenging to become skilled in percutaneous surgery; however, this expertise is necessary to achieve successful and safe outcomes. Furthermore, radiation exposure poses a risk to both the patients and surgeon.

2. Bone transplantation is impossible with MISt. Atanasiu et al. [21] reported that bone transplantation is required for patients with a life expectancy of 2 years or longer. In cases of long-term survival contrary to the prognosis, it is necessary to consider whether additional bone grafting should be performed. However, in the present study, only 2 of the 51 patients underwent reoperation due to loosening of the screws. The results of adjuvant therapy have been improved by advances in radiotherapy, bisphosphonates, and various chemotherapies. Bellato [22] reported that 9 of $105(8.57 \%)$ patients with cancer who underwent spinal fusion experienced mechanical failure; the mean time to failure was 9.5 months, and the most common failure was implant loosening. Furthermore, the mean and median durations of survival were 22.76 and 7.4 months, respectively. Thus, $88 \%$ of patients had a shorter survival duration than the average time required to develop mechanical complications. The authors noted that no cases required further surgery. In our opinion, temporary fixation with MISt is appropriate until unstable lesional vertebral bodies are remodeled and become stable.

3. Even MISt is associated with postoperative pain. In many cases, patients with cancer experience severe preoperative pain and are receiving high doses of morphine. MISt is a minimally invasive procedure; however, controlling postoperative pain is often difficult.

As discussed above, MISt is a useful treatment for metastatic spinal tumors. It provides hope to patients who were previously ineligible for treatment because they did not qualify for conventional invasive surgeries. Uei et al. [13] reported the results of multidisciplinary treatment using palliative posterior spinal stabilization surgery, and the median postoperative survival time was 12 months. We used the same combination of multidisciplinary treatment and spinal stabilization as Uei et al. [13]. The median survival time in our study was $22.0 \pm 8.6$ months in our study. MISt also allows for early hospital discharge, which is beneficial given the current shift of cancer treatment to outpatient settings.

On the other hand, the indications for surgery are also important. We should avoid choosing surgery easily because it is less invasive. Although there are some reports that an interdisciplinary discussion was carried out and decide on surgery before surgery [18], most 
of the indications for surgery are intolerable back pain, neurologic deficits, compression, spinal instability, and resistance to conservative treatment $[13,23]$. There are many reports using SINS to evaluate spinal instability, but the indications for SINS in cases of imminent instability of 7 to 12 points are ambiguous and depend largely on the surgeon's preference. In our hospital, not only SINS, but also further strict indications, were set and surgery was performed, but it is necessary to study the indications of MISt for this disease with more cases.

Furthermore, surgery for appropriate patients at appropriate times prolongs life expectancy, even in the context of spinal metastases. Watanabe et al. [17] and HelwegLarsen et al. [24] reported that the severity of preoperative paralysis had a significant impact on final walking ability. After paralysis has occurred, the results are not good, even if the operation is performed with MISt. It is also important to detect the disease at an early stage by using multidisciplinary treatment, as in this study. Our results are due to the fact that we intervene early in all metastatic spine tumors [6]. Rather than providing palliative or urgent treatment to all patients, it is advisable to detect candidate patients as early as possible and to restore spine-related functions with less invasive surgery before these functions are lost and neurological symptoms occur.

\section{Limitations}

Future issues to be addressed include the small number of cases in the surgery group and the lack of analysis of each type of carcinoma. The lack of a control in this study is also considered a limitation.

\section{Conclusions}

1. MISt for metastatic spinal tumors is a useful surgery, particularly in light of the recent shift to outpatient cancer treatment;

2. MISt can improve the outcome of patients who are ineligible for conventional, highly invasive surgery;

3. Choosing the right surgery for the right patient at the right time has a significant impact on life expectancy.

Author Contributions: Conceptualization, K.N., K.U., S.W., K.M. and H.I.; data curation, K.N., K.U., S.W., K.M. and H.I.; writing — original draft preparation, K.N.; writing—review and editing, K.N.; supervision, K.N. All authors have read and agreed to the published version of the manuscript.

Funding: This research received no external funding.

Institutional Review Board Statement: The study was conducted according to the guidelines of the Declaration of Helsinki and approved by the Institutional Review Board of our hospital (ID: 5054-01, 20 October 2020).

Informed Consent Statement: Informed consent was obtained from all subjects involved in the study.

Data Availability Statement: Not applicable.

Conflicts of Interest: The authors declare no conflict of interest.

\section{References}

1. Cook, R.J.; Major, P. Methodology for treatment evaluation in patients with cancer metastatic to bone. J. Natl. Cancer Inst. 2001, 93, 534-538. [CrossRef] [PubMed]

2. Saad, F.; Gleason, D.M.; Murray, R.; Tchekmedyian, S.; Venner, P.; Lacombe, L.; Chin, J.L.; Vinholes, J.J; Goas, J.A.; Chen, B. A randomized, placebo-controlled trial of zoledronic acid in patients with hormone-refractory metastatic prostate carcinoma. J. Natl. Cancer Inst. 2002, 94, 1458-1468. [CrossRef] [PubMed]

3. Ibrahim, T.; Flamini, E.; Fabbri, L.; Serra, P.; Mercatali, L.; Ricci, R.; Sacanna, E.; Falasconi, M.C.; Casadei, R.; Galassi, R.; et al. Multidisciplinary approach to the treatment of bone metastases: Osteo-Oncology Center, a new organizational model. Tumori 2009, 95, 291-297. [CrossRef] [PubMed] 
4. Howard, L.E.; De Hoedt, A.M.; Aronson, W.J.; Kane, C.J.; Amling, C.L.; Cooperberg, M.R.; Terris, M.K.; Divers, C.H.; Valderrama, A.; Freedland, S.J. Do skeletal-related events predict overall survival in men with metastatic castration-resistant prostate cancer? Prostate Cancer Prostatic Dis. 2016, 19, 380-384. [CrossRef]

5. Tomita, K.; Kawahara, N.; Baba, H.; Tsuchiya, H.; Nagata, S.; Toribatake, Y. Total en block spondylectomy for solitary spinal metastases. Int. Orthop. 1994, 18, 291-298. [CrossRef]

6. Nakanishi, K.; Uchino, K.; Watanabe, S.; Iba, H.; Hasegawa, T. Liaison treatment for metastatic spinal tumors. Spine Surg. Relat. Res. 2020, 4, 223-228. [CrossRef]

7. $\quad$ Fisher, C.G.; DiPaola, C.P.; Ryken, T.C.; Bilsky, M.H.; Shaffrey, C.I.; Berven, S.H.; Harrop, J.S.; Fehlings, M.G.; Boriani, S.; Chou, D.; et al. A novel classification system for spinal instability in neoplastic disease: An evidence-based approach and expert consensus from the Spine Oncology Study Group. Spine 2010, 35, E1221-E1229. [CrossRef]

8. Nakanishi, K.; Hasegawa, T.; Tanaka, M.; Ikuma, H.; Shiozaki, Y.; Yamane, K. Application of mnimally invasive spine stabilization (MISt) for metastatic spine tumors. J. MIOS 2013, 68, 61-67.

9. Bilsky, M.H.; Laufer, I.; Fourney, D.R.; Groff, M.; Schmidt, M.H.; Varga, P.P.; Vrionis, F.D.; Yamada, Y.; Gerszten, P.C.; Kuklo, T.R. Reliability analysis of the epidural spinal cord compression scale. J. Neurosurg. Spine 2010, 13, 324-328. [CrossRef]

10. Tokuhashi, Y.; Matsuzaki, H.; Oda, H.; Oshima, M.; Ryu, J. A revised scoring system for preoperative evaluation of metastatic spine tumor prognosis. Spine 2005, 30, 2186-2191. [CrossRef]

11. Katagiri, H.; Okada, R.; Takagi, T.; Takahashi, M.; Murata, H.; Harada, H.; Nishimura, T.; Asakura, H.; Ogawa, H. New prognostic factors and scoring system for patients with skeletal metastasis. Cancer Med. 2014, 3, 1359-1367. [CrossRef] [PubMed]

12. Oken, M.M.; Creech, R.H.; Tormey, D.C.; Horton, J.; Davis, T.E.; McFadden, E.T.; Carbone, P.P. Toxicity and response criteria of the Eastern Cooperative Oncology Group. Am. J. Clin. Oncol. 1982, 5, 649-655. [CrossRef]

13. Uei, H.; Tokuhashi, Y.; Maseda, M.; Nakahashi, M.; Sawada, H.; Nakayama, E.; Soma, H. Clinical results of multidisciplinary therapy including palliative posterior spinal stabilization surgery and postoperative adjuvant therapy for metastatic spinal tumor. J. Orthop. Surg. Res. 2018, 13, 30. [CrossRef] [PubMed]

14. Yang, Z.; Yang, Y.; Zhang, Y.; Zhang, Z.; Chen, Y.; Shen, Y.; Han, L.; Xu, D.; Sun, H. Minimal access versus open spinal surgery in treating painful spine metastasis: A systematic review. World J. Surg. Oncol. 2015, 13, 68. [CrossRef] [PubMed]

15. Zuckerman, S.L.; Laufer, I.; Sahgal, A.; Yamada, Y.J.; Schmidt, M.H.; Chou, D.; Shin, J.H.; Kumar, N.; Sciubba, D.M. When less is more: The indications for MIS techniques and separation surgery in metastatic spine disease. Spine 2016, 20, S246-S253. [CrossRef]

16. Miscusi, M.; Polli, F.M.; Forcato, S.; Ricciardi, L.; Frati, A.; Cimatti, M.; De Martino, L.; Ramieri, A.; Raco, A. Comparison of minimally invasive surgery with standard open surgery for vertebral thoracic metastases causing acute myelopathy in patients with short- or mid-term life expectancy: Surgical technique and early clinical results. J. Neurosurg. Spine 2015, 22, 518-525. [CrossRef]

17. Watanabe, N.; Sugimoto, Y.; Tanaka, M.; Mazaki, T.; Arataki, S.; Takigawa, T.; Kataoka, M.; Kunisada, T.; Ozaki, T. Neurological recovery after posterior spinal surgery in patients with metastatic epidural spinal cord compression. Acta Med. Okayama 2016, 70, 449-453.

18. Hansen-Algenstaedt, N.; Kwan, M.K.; Algenstaedt, P.; Chiu, C.K.; Viezens, L.; Chan, T.S.; Lee, C.K.; Wellbrock, J.; Chan, C.Y.W.; Schaefer, C. Comparison Between Minimally Invasive Surgery and Conventional Open Surgery for Patients with Spinal Metastasis: A Prospective Propensity Score-Matched Study. Spine 2017, 42, 789-797. [CrossRef]

19. Cui, Y.; Shi, X.; Mi, C.; Wang, B.; Pan, Y.; Lin, Y. Comparison of Minimally Invasive Tubular Surgery with Conventional Surgery in the Treatment of Thoracolumbar Metastasis. Cancer Manag. Res. 2021, 13, 8399-8409. [CrossRef]

20. Zairi, F.; Arikat, A.; Allaoui, M.; Marinho, P.; Assaker, R. Minimally invasive decompression and stabilization for the management of thoracolumbar spine metastasis. J. Neurosurg. Spine 2012, 17, 19-23. [CrossRef]

21. Atanasiu, J.P.; Badatcheff, F.; Pidhorz, L. Metastatic lesions of the cervical spine-A retrospective analysis of 20 cases. Spine 1993, 18, 1279-1284. [CrossRef] [PubMed]

22. Bellato, R.T.; Teixeira, W.G.; Torelli, A.G.; Cristante, A.F.; Barros, T.E.; Camargo, O.P. Late failure of posterior fixation without bone fusion for vertebral metastases. Acta Ortop. Bras. 2015, 23, 303-306. [CrossRef] [PubMed]

23. Pranata, R.; Lim, M.A.; Vania, R.; Mahadewa, T.G.B. Minimal Invasive Surgery Instrumented Fusion versus Conventional Open Surgical Instrumented Fusion for the Treatment of Spinal Metastases: A Systematic Review and Meta-analysis. World Neurosurg. 2021, 148, 264-274. [CrossRef] [PubMed]

24. Helweg-Larsen, S.; Sørensen, P.S.; Kreiner, S. Prognostic factors in metastatic spinal cord compression: A prospective study using multivariate analysis of variables influencing survival and gait function in 153 patients. Int. J. Radiat. Oncol. Biol. Phys. 2000, 46, 1163-1169. [CrossRef] 